\title{
Parental occupations and cancer: a review of the literature
}

\author{
S E ARUNDEL AND L M KINNIER-WILSON \\ From the Cancer Epidemiology Research Unit, Department of Social Medicine, University of Birmingham
}

SUMMARY Parental occupation is a suspected risk factor in the occurrence of childhood cancer. Fourteen epidemiological studies investigating a possible association are reviewed and observations are found to be contradictory. Several reports show significant associations for occupations involving exposure to hydrocarbons, lead or chemicals and occupations of social classes I and II. Conversely, some studies find no association at all. Methodological variations do not account for the contrasting results so further investigation is required.

Little is known for certain about the causes of malignant disease in children, although in developed countries it is a main cause of death in childhood after the first year, excluding accidents. Suggested risk factors include maternal obstetric $x$ rays, pharmaceutical drugs and certain virus infections during pregnancy, parental age, birth order, and parental occupation. This report is concerned with the possible influences of parental occupation.

The theory of a correlation between parental occupation and childhood cancer is perfectly plausible and there are several possible mechanisms by which this relation could arise: firstly, by effect of germ cell mutation in either parent exposed to an occupational noxious agent in the period leading to conception. Certain known carcinogens such as hydrocarbons have been shown to have an effect on spermatogenesis; and, similarly, maternal exposure before and during pregnancy may lead to damage of germ cells. Secondly, exposure of the mother before and during pregnancy and during lactation to soiled clothing brought home from the father's workplace may lead to chromosome defects, for example, lead appears to have the capacity to cause chromosomal changes after short exposures to relatively small doses and at blood levels long considered compatible with normal physiological function. Thirdly, exposure of the child to the repeated or continued presence of certain items in the household or prolonged contact with the father's contaminated clothing may cause direct carcinogenesis.

During the last decade there have been several epidemiological studies concerning the possible association between parental occupation and cancer in childhood which have produced conflicting evidence. Of 14 reports, eight say there is ant association and six the converse. Each was conducted by a similar method. Childhood cancer cases were collected together; controls were selected according to sex, age, domicile, or other properties; theo $z$ paternal (and, in some reports, maternal) occupation was obtained and categorised; and statistical analysiơ 웅 was carried out. There are, however, several minor differences within the basic method outlined above for example, source of information, type of case, and categorisation of parental occupation. These must be borne in mind when attempting to compare survey results. The reports are reviewed in chronological order in two categories: those finding associations (positive reports) and those not (negative reports).

\section{Positive reports}

The first such study was conducted in 1974 in Canada by Fabia and Thuy. ${ }^{1}$ They compared the paternal occupations of 386 children who died of malignant disease before the age of 5 in the province of Quebec with those of 772 control children (children whose birth registration immediately preceded and followed that of each case in the official files). Information regarding the cases was obtained from three sources: death certificates, hospital insurance data, and hospital records. Paternal occupations were obtained from birth certificates, presumably referring to work performed before the children were born, and then grouped "according to guidelines given by a specialist in industrial hygiene". Results revealed a significant excess of fathers in hydrocarbon-related occupations. Of the 386 cases, 71 fathers were employed in hydrocarbon-related 
occupations (18.39\%); and of the 772 controls, 75 $(9 \cdot 7 \%)$, giving an odds ratio (OR) of $2 \cdot 1$.

Five years later, in 1979 , a study was performed by Kantor $e t a l^{2}$ in the USA to investigate a possible relation between Wilms' tumour and paternal occupation. Their subjects were 149 children aged 0-19 years with Wilms' tumour, reported to the Connecticut Tumour Registry, and 149 control children selected from the Connecticut State Health Department files of birth certificates and matched for sex, race, and year of birth. The paternal occupations were extracted from birth certificates and their classification was similar to that of Fabia and Thuy.

Results revealed a significant case excess for paternal occupations involving lead. Of 149 cases 22 $(14 \cdot 77 \%)$ and of 149 controls $6(4.03 \%)$ had fathers in lead related occupations, giving an OR of $3 \cdot 7$. The authors did find an OR of 2.4 for hydrocarbon-related occupations, but this group was contributed largely by occupations in which exposure to lead is known to occur, and further analysis showed lead to be the important factor.

Soon after, Kwa and Fine $^{3}$ carried out an investigation to test Fabia and Thuy's findings. Their study comprised 692 children who were born during 1947-57 and 1963-67 and died of cancer before the age of 15 in Massachusetts, and 1384 control children (two for each case) whose birth registration immediately preceded and followed that of the case subject. Parental occupations were obtained from birth certificates. Results proved negative concerning hydrocarbon-related occupations, but when the cancers were subdivided into four main categories two other associations emerged: (1) paternal employment as paper or pulp mill worker and nervous system tumours; and (2) paternal employment as mechanic or machinist and tumours of the urinary tract.

In 1981, Hemminki et al $^{4}$ carried out a study on childhood cancer and parental occupation in Finland. The series included all 1600 childhood cancer cases, diagnosed in children under 15 years, reported to the Finnish Cancer Registry during the period 1959-75. This time scale was divided into two periods, 1959-68 and 1969-75. For the 1958-68 series, one control child (born next after the case) was selected, and in the 1969-75 series two control children were selected, one born next before and one next after the case child in the same maternity welfare district. The information on parental occupation was collected from the records of the welfare centres attended by the mothers during pregnancy. Odds ratios were calculated to evaluate effects of the different occupations for both parents. The results were somewhat ambiguous, and the analysis involved small numbers. It appeared that mothers' occupations carrying significant risk were farmers' wives and those related to the food industry. When maternal occupations were studied according to diagnostic category it was found that pharmacy was significantly related to all malignancies. In paternal occupations, agricultural workers and men with academic degrees showed significant case excess, and children with leukaemia had a greater percentage of fathers who were motor vehicle drivers.

In the same year in Los Angeles, Peters, Preston-Martin, and $\mathrm{Yu}^{5}$ also found a relationship between the occupations of both parents and childhood cancer. Cases were children with brain tumours, aged less than 10 at diagnosis, identified between 1972 and 1977 by the Los Angeles County Cancer Surveillance Program. Controls were selected by sex, race, age, and social class, giving 92 matched pairs. Interviews were conducted by telephone, and occupations were grouped by method of exposure rather than by name of chemical, for example, contact on skin and fumes inhaled. Information on job exposures were obtained for the time periods before conception, during pregnancy, and at diagnosis. Results were as follows: for maternal chemical exposure to skin there were 10 discordant pairs where the case was involved and 3 for the controls, giving a relative risk of $3 \cdot 3$. For maternal inhaled substances there were 12 discordant pairs with the case exposed and 4 with the control, giving RR 3.0. For paternal exposure to solvents the numbers were 17 and 6 respectively, giving RR $2 \cdot 8$. In addition, a strong association was found between paternal employment in the aircraft industry where solvents and chemicals were used.

McWhirter's study in Australia in 1982 showed a relation between childhood lymphoblastic leukaemia (ALL) and social class. The data were gathered by the Queensland Childhood Malignancy Registry and included cases which occurred during the period 1973-79 (127 cases of ALL). The incidence of ALL in each of 12 areas in Queensland was compared with some demographic factors for each of those areas. A statistically significant positive correlation was found between ALL and the proportion of the population with tertiary qualifications, and a negative correlation between ALL incidence and the proportion of the population in farming, labouring occupations, etc. A similar result was found when Brisbane City was divided into suburbs and studied separately. Where less than $8.0 \%$ of the population were in professional or technical occupations, there were six cases of ALL, giving an age-specific incidence of 2.4 per 100000 . Where $8 \cdot 0-15 \cdot 9 \%$ were in such occupations, there were 26 cases of ALL, giving an age-specific incidence of 3.8 per 100000 , and where $16.0 \%$ or more were in these 
occupations there were 19 cases, giving an age-specific incidence of 7.2. A similar pattern emerged when comparing proportions of students at non-government schools with the incidence of ALL.

The survey of Hicks et $^{7} \mathrm{l}^{7}$ in 1984 concentrated on the effects of occupational radiation exposure. The 298 case children were identified from the medical records of the Hematology-Oncology Service of the Texas Children's Hospital in Houston, Texas. They had been treated for cancer during the period March 1976 through December 1977. There were three sets of controls: parents of children without cancer seen at the clinic during the same interval; siblings of the parents in the case group; neighbourhood parents of children who did not have cancer and who were about the same ages as the case children. Information was obtained from face-to-face or telephone interviews as well as from clinic records. Occupations involving potential exposure to ionising radiation were identified and then classified as to the quantity of radiation. No association was found between childhood cancer risk and parental occupation when one or both parents were exposed to ionising radiation compared with those in which neither parent was exposed. However, bone cancer and Wilms' tumour occurred more frequently in children of fathers with moderate exposure. Children with cancer more often had fathers who were aircraft mechanics $(\mathrm{N}=6, \mathrm{OR}=x)$. Certain types of cancer were found to be more common among children of fathers in specific radiation related occupations: rhabdomyosarcoma among children whose fathers were petroleum industry foremen $(\mathrm{N}-2, \mathrm{OR}-\infty)$; retinoblastoma among children whose fathers were radio and television repairmen (N-2, OR-31.44); CNS cancers $(\mathrm{N}-4, \mathrm{OR}-8 \cdot 88)$ among children of air force men.

In 1985, van Steensel-Moll et al, ${ }^{8}$ from the Dutch Childhood Leukaemia Study Group, produced a register based case-control study. The 519 cases were selected from a nationwide register diagnosed between 1973 and 1980. Controls (507) were matched for date of birth, sex, and place of residence at time of diagnosis. A positive relation was found for mothers working during pregnancy in hydrocarbon-related occupations (printing, dyeing, petrol station attendant), relative risk (RR) $2 \cdot 5$, and with occupational exposure to chemicals (paint, petroleum products, and unspecified chemicals), $R \mathbf{R}$ $2 \cdot 4$. No positive relation was established for mothers' occupations one year before diagnosis, nor for fathers' occupations either during pregnancy or a year before diagnosis.

\section{Negative reports}

The first such study was that of Hakulinen, Salonen, and Teppo ${ }^{9}$ in Finland in 1976, who investigated the same question as Fabia and Thuy for a possible connection between childhood cancer and hydrocarbon-related occupations. They studied 852 cancer cases reported to the Finnish Cancer Registry in 1959-68 and 852 controls matched for date of birth and domicile. All fathers' occupations were ascertained from the records of antenatal clinics and were therefore relevant to the first trimester of the pregnancy. Risk ratios did not differ significantly from 1. For example, the risk ratio in respect of motor-vehicle mechanics for all tumours was $1 \cdot 17$ (7/6 children). Other risk ratios were well within confidence limits.

In 1980 , Zack et al ${ }^{10}$ completed a similar report in the USA - the Texas Childhood Cancer Study 1976-77. They investigated the paternal occupations of 296 children with cancer who were followed at Texas Children's Hospital Research Hematology Clinic during 1976-77. They had three sets of controls: (1) parents of children without cancer attending the clinic at the same time; (2) siblings of the parents of the case group; (3) neighbours of the case parents matched for number and age of thein children. Accurate information was obtained by face-to-face or telephone interviews, and statisticaf tests were carried out. They found that parents of the case children were not exposed tœ hydrocarbon-related occupations or industries more often than the control parents. There were 12 father in hydrocarbon-related occupations, 18 uncles, $F$ male neighbours, and 22 fathers of controls, giving ORs $0.93,1.33$, and 0.50 respectively, all well within 95\% confidence limits. This lack of association persisted for all other analyses including occupations the year after birth, the year before diagnosis, interval from year before birth to year of diagnosis, for different diagnosis, for different ages at diagnosis, and for the industries and occupations of mothers, too.

Sanders, White and Draper ${ }^{11}$ conducted their study one year later in Britain. They analysed the paternal occupations for all children dying in England and Wales during the years $1959-63$ and 1970-72, comparing those dying from neoplasms (over 6000) with those dying from other causes. Fathers' occupations were obtained from death certificates and coded according to the United Kingdom Standard Classification of Occupations. Analysis was performed by proportional mortality ratios. The two most strikingly high PMRs were for deaths from neoplasms among children of fathers in occupations of social classes 1 and 2, for example, in the category for administrators and managers and for technical workers and artists, whereas a low value was obtained for children of fathers who were 
labourers, reflecting the same correlation as that discovered by McWhirter. When PMRs for deaths among children of fathers in hydrocarbon-related occupations were evaluated, no general association emerged. For separate categories of neoplasm among children of fathers in hydrocarbon-related occupations, slightly raised PMRs were noted for kidney tumours but not significantly.

In a study a year later by Gold, Diener, and Szklo, ${ }^{12}$ the occupations and occupational exposures of parents before and after the birth of a child who later developed leukaemia or a brain tumour were compared with the occupational experience of parents of children with other cancers and of normal children. Forty-three children diagnosed with leukaemia in 1969-74 and 70 children diagnosed with brain tumours in 1965-74 in the Baltimore Standard Metropolitan Statistical Area were ascertained from hospital records and death certificates. The first control group were children with no known malignant disease, selected from birth certificates at the Marylands State Health Department and matched for date of birth, sex, and race. The second control group (cancer controls) were children with malignancies other than leukaemia or brain tumours and matched for sex, date of diagnosis, age at diagnosis, and race. This group was used for two reasons: (1) to see whether factors associated with leukaemia or brain tumours were also associated with other malignancies in children; (2) to determine if selective recall bias by parents of seriously ill children played an important role in the study. Information was obtained by interviewing the mothers. The only significant differences found were: (1) for the mother, vehicle-related occupations between leukaemia patients and their cancer controls in the prenatal period (OR-6.2); (2) for hydrocarbon-related occupations between brain tumour patients and their matched controls in the postnatal period. Thus statistically significant associations were observed in comparisons of patients with their matched cancer controls, not the normal controls.

In 1984 , the study of Shaw et $a^{13}$ also yielded negative results concerning any association between childhood leukaemia and paternal occupation. The study included cases of leukaemia among children born after 1964 that were reported to the California Tumour Registry and diagnosed between 1975 and 1980. Altogether, there were 255 cases with two controls for each case, found by selecting the birth certificates of the same sex immediately preceding and following the index case. Information was obtained from birth certificates. For paternal benzene exposure, cases and controls were similar $(76 \%$ and $75 \%$ respectively). For purposes of comparison, the occupational data were grouped in the same manner as in the study of Fabia and Thuy. No significant differences were found between cases and controls for these hydrocarbon-related occupational groups.

Finally, in the same year, Wilkins and Sinks ${ }^{14}$ re-examined the hypothesis regarding Wilms' tumour and paternal occupations with exposure to lead and hydrocarbons. Sixty-two patients with Wilms' tumour were identified through the Columbus (Ohio) Children's Hospital Tumour Registry. For each case in the study the birth certificates of two children were randomly selected from the Ohio birth certificate files to serve as controls: in the first control group, children were individually matched with respect to sex, race, and year of birth, and in the second control group they were similarly matched with, additionally, the mother's county of residence when the child was born. All information was obtained from birth certificates. The results are as follows: for hydrocarbon-related occupations (narrow definition) $O R=1 \cdot 37$, for hydrocarbon-related occupations (broad definition) $O R=1.40$, for lead-related occupations $O R=1 \cdot 25$, and for painters $\mathrm{OR}=6 \cdot 00$.

\section{Discussion}

It seems impossible to conclude whether or not there is a relation between parental occupation and childhood cancer, since these reports are not directly comparable and they vary widely in areas fundamental to the study. The source of information is probably one of the most important variables, and several of these reports used either birth or death certificates which are often inaccurate.

Peters et al, ${ }^{5}$ Hicks et al, ${ }^{7}$ Zack et al, ${ }^{10}$ and Gold et $a l^{12}$ obtained their information by personal interview, which is a more reliable source but not always possible. Secondly, some studies had incomplete coverage: Hemminki et $a l,{ }^{4} \mathrm{McWhirter}^{6}{ }^{6}$ and Hakulinen et $a l^{9}$ had cases which were either lost or discarded, and this could lead to bias in the results. Gold et al, ${ }^{12}$ Sanders $e t a l,{ }^{11}$ and Kantor et $a l^{2}$ managed to include all potential cases, but Sanders $e t$ $a l^{11}$ used cancer deaths as opposed to incident and the fathers' occupations were taken from death certificates and so may have missed the important preconception period. Thirdly, some control groups were more carefully selected than others: Fabia and Thuy, ${ }^{1} \mathrm{~K}$ wa and Fine, ${ }^{3}$ and Hemminki et al ${ }^{4}$ matched their controls only by birth registration, whereas Peters et al matched for sex, race, age, and social class. Fourthly, not all of these studies included the occupations of both parents. If there is an association 
between parental occupation and childhood cancer, then the occupation of the mother is just as important as that of the father. Only Hemminki et al, ${ }^{4}$ Peters et al, ${ }^{5} \mathrm{McWhirter},{ }^{6} \mathrm{Hicks}$ et al,${ }^{7} \mathrm{Zack}$ et al,${ }^{10} \mathrm{Gold}$ et al,${ }^{12}$ and van Steensel-Moll et $a l^{8}$ included both parents. This last study also had a carefully selected control group, used personal interviews, had national coverage, and was the only one to specially highlight pregnancy occupations.

There is a serious statistical problem in the way some studies have examined a wide range of different parental occupations and cancer types, eg, Hemminki et al, ${ }^{4} \mathrm{Kwa}$ and Fine, ${ }^{3}$ Hakulinen et al, ${ }^{9}$ and Sanders et al, ${ }^{11}$ while others have concentrated on much smaller numbers, with specifically chosen cancer categories; eg, Kantor et al, ${ }^{2}$ Peters et al, ${ }^{5}$ McWhirter, ${ }^{6}$ Gold et al, ${ }^{12}$ and Wilkins and Sinks ${ }^{14}$. The large non-specific studies are so wide that they were almost certain to highlight some apparent difference, so that the findings of Kwa and Fine ${ }^{3}$ and Hemminki et $\mathrm{l}^{4}$ should only be considered seriously if validated by subsequent studies. The study by van Steensel-Moll et $a l^{8}$ has over 500 cases but they are all specifically limited to leukaemia.

There are also problems of differentiating occupational risks from social class and residential effects. McWhirter's study ${ }^{6}$ found that there was a positive significant association between ALL and the upper social classes and a negative correlation with lower social classes. Since the same trend was seen in the whole state of Queensland and in the small area of Brisbane City these results must be attributed to population characteristics rather than geographical factors. There are several possible explanations for this: first, factors associated with differences in lifestyle among the various social classes may increase or decrease the risk of developing ALL; secondly, Stewart and her colleagues ${ }^{15}$ have suggested that children in a pre-leukaemia phase have an increased tendency to infections, and it is possible that the children in lower social class families with higher risk of infections die before their leukaemia is recognised; or, thirdly, it may be an artefact, though this appears less likely when the findings of Sanders $e t a^{11}$ are also considered. They found the most strikingly high proportional mortality ratios were for cancer deaths in children of social classes 1 and 2 , whereas the lowest values were among children whose fathers were in social class 5 . However, in spite of all these difficulties in addressing the problem of multiple comparisons, the positive results of Kantor et al, ${ }^{2}$ Peters et al, ${ }^{5}$ and van Steensel-Moll et al, ${ }^{8}$ along with those of Fabia and Thuy, ${ }^{1}$ establish the hypothesis of hydrocarbon and lead exposed jobs being potentially hazardous for both the father and the mother in pregnancy.
Considering the several potential cancer categories involved, all the many occupations and industries, and conflicting factors such as drugs and smoking, it would appear that large numbers of cases and better information on both histological diagnosis and parental occupation exposure will be necessary if more definitive answers are to be obtained.

This study was supported by US Department of Health and Human Services 223786017 MRC G 8126057.

Reprint requests to: LM Kinnier-Wilson, CERU, Department of Social Medicine, University of Birmingham, Birmingham B15 2TH.

\section{References}

${ }^{1}$ Fabia J, Thuy TD. Occupation of father at time of birth of children dying of malignant diseases. Br J Prev Soc Med 1974; 28: 98-100.

${ }^{2}$ Kantor AF, McCrea Curnen MG, Wister Meigs J, Flannery JF. Occupations of fathers of patients with Wilms' tumour. J Epidemiol Community Health 1979. 33: 253-6.

${ }^{3} \mathrm{Kwa}$ SL, Fine LJ. The association between parentald occupation and childhood malignancy. J Occup Med 1980; 22: 12.

${ }^{4}$ Hemminki K, Saloniemi I, Salonen T, Partanen T, Vainio H. Childhood cancer and parental occupation if Finland. J Epidemiol Community Health 1981; 35 11-5.

${ }_{5}^{5}$ Peters JM, Preston-Martin S, Yu MC. Brain tumours in children and occupational exposure of parents. Science 1981; 213: 235-6.

${ }^{6}$ McWhirter WR. The relationship of incidence of childhood lymphoblastic leukaemia to social class. $\mathrm{Br} \mathbf{J}$ Cancer 1982; 46: 640-5.

${ }^{7}$ Hicks N, Zack M, Caldwell GG, Fernbach DJ, Falletta JM. Childhood cancer and occupational radiation exposure in parents. Cancer 1984; 53: 1637-43.

${ }^{8}$ van Steensel-Moll HA, Valkenburg HA, van Zanen GE. Childhood leukaemia and parental occupation: a register-based case control study. Am J Epidemiol 1985; 121: $216-24$.

${ }^{9}$ Hakuliner T, Salonen T, Teppo L. Cancer in the offspring of fathers in hydrocarbon-related occupations. Br J Prev Soc Med 1976; 30: 138-40.

${ }^{10}$ Zack M, Cannon S, Loyd D, et al. Cancer in children of parents exposed to hydrocarbon-related industries and occupations. Am J Epidemiol 1980; 111: 329-36.

${ }^{11}$ Sanders BM, White GC, Draper GJ. Occupations of fathers of children dying from neoplasms. J Epidemiol Community Health 1981; 35: 245-50.

${ }^{12}$ Gold EB, Diener MD, Szklo M. Parental occupations and cancer in children. $J$ Occup Med 1982; 24: 578-84.

${ }^{13}$ Shaw G, Lavey R, Jackson R, Austin D. Association of childhood leukaemia with maternal age, birth order and paternal occupation. Am J Epidemiol 1984; 119: 788-95.

${ }^{14}$ Wilkins JR, Sinks TH. Paternal occupation and Wilms' tumour in offspring. $J$ Epidemiol Community Health 1984; 38: 7-11.

${ }^{15}$ Kneale GW, Stewart AM. Pre-cancers and liability to other diseases. Br J Cancer 1978; 37: 448-57. 
Summary Table

\begin{tabular}{|c|c|c|c|c|}
\hline Reference & Case group & Control group & Source of information & Conclusions \\
\hline $\begin{array}{l}\text { Fabia and Thuy } \\
1974\end{array}$ & $\begin{array}{l}\text { Fathers of } 386 \text { Quebec children } \\
\text { who died from cancer before age } \\
5 \text { during } 1965-70\end{array}$ & $\begin{array}{l}\text { Fathers of } 772 \text { children whose } \\
\text { birth registration immediately } \\
\text { preceded and followed that of } \\
\text { each case ( } 2 \text { per case) }\end{array}$ & Birth certificates & $\begin{array}{l}\text { Significant excess of fathers in } \\
\text { hydrocarbon-related occupations } \\
\text { (machinists, miners, mechanics, and } \\
\text { painters) } \\
\text { Odds ratio }=2 \cdot 1\end{array}$ \\
\hline
\end{tabular}

Kantor et al
1979

Kwa and Fine 1980

Hemminki et al

1981

Peters et al

1981

McWhirter

1982

Hicks et al

1984 tumour cases (age 0-19 yr) reported to the Connecticut Tumor Registry 1935-73

Fathers of 692 children born during 1947-57 and 1963-67 who died of cancer before age 15 in Massachusetts
Fathers of 149 incident Wilms'
Fathers of 149 children matched for sex, race, and year of birth

Fathers of 1384 children whose birth registration immediately preceded and followed that of each case child
Birth certificates

Birth certificates

Records of welfare

For the 1959-68 cases: parents of the child born next after the case

For the 1969-75 cases: parents of the children born next before and next after the case (aged under 15) of ALL which occurred during 1973-79 gathered by the Queensland Childhood Malignancy Registry

Parents of 298 cases of childhood cancer identified from the Texas Children's Hospital, treated for cancer during March 1976-December 1977
Demographic factors for the relevant area

Parents of 92 children matched by sex, race, age, and social class

Telephone interviews

Three groups:

Parents of children without cancer seen at the clinic during the same interval

Siblings of parents in case group Neighbourhood parents of children who did not have cancer and who were about the same ages as the case children

Face-to-face or telephone interviews and clinic records van Steensel-Moll et al

1985
Parents of 519 children with ALL selected from nationwide register of childhood leukaemia in the Netherlands 1973-80
Parents of 507 children matched for sex and birth date and same municipal area as case children
Parents of 852 children matched

Fathers of 852 incident cance cases reported to the Finn
Cancer Registry 1959-68
Postal questionnaires to parents
Records of antenatal clinics
A positive statistically significant association between fathers' occupations involving lead and offspring with Wilms' tumour Odds ratio $=3 \cdot 7$

Positive association between paternal occupation as paper or pulp mill worker and nervous system tumours (relative odds $2 \cdot 8$ ); positive association between paternal occupation as mechanic or machinist and tumours of the urinary tract (relative odds 2.5); no association with hydrocarbon-related occupations

Maternal occupations found significantly more frequently among cases than controls included farmers wives, pharmacists, saleswomen, bakers, and factory workers. Paternal risk occupations appeared to be farming, motor vehicle driving, machine repair, painting and work of men who gave academic degrees as their occupation.

Association between brain tumours and maternal exposure to chemicals, paternal exposure to solvents, and paternal employment in the aircraft industry

Positive significant association between ALL and social class $(p=0.001)$

Parents of children with cancer were no more likely to have worked in occupations with potential ionising radiation exposure.

Children with cancer more often had fathers who were aircraft mechanics $(p=0.04)$.

Children whose fathers had military jobs with potential ionising radiation had an increased cancer risk $(p=0.01)$.

Specific cancer types occurred significantly more often among children of fathers in certain radiation-related occupations

Positive association between mothers' pregnancy occupations (hydrocarbon-related and chemicals related), RR-25 and 24. Mothers pre-occupations and fathers pre-diagnosis occupations showed no relation.

No significant associations between childhood cancer and hydrocarbon-related occupations Risk ratios $=1$ 
Summary Table—continued

\begin{tabular}{|c|c|c|c|c|}
\hline Reference & Case group & Control group & Source of information & Conclusions \\
\hline $\begin{array}{l}\text { Zack et al } \\
1980\end{array}$ & $\begin{array}{l}\text { Parents of } 296 \text { children with } \\
\text { cancer who were followed at } \\
\text { Texas Children's Hospital } \\
\text { Research Hematology Clinic } \\
\text { during March 1976-December } \\
1977\end{array}$ & $\begin{array}{l}\text { Three groups: } \\
\text { Parents of children without } \\
\text { cancer attending clinic at same } \\
\text { time } \\
\text { Siblings of parents of case group } \\
\text { Neighbours of case parents } \\
\text { matched for number and age of } \\
\text { children }\end{array}$ & $\begin{array}{l}\text { Face-to-face or } \\
\text { telephone interviews }\end{array}$ & $\begin{array}{l}\text { No association between } \\
\text { hydrocarbon-related occupations } \\
\text { and childhood cancer for any } \\
\text { case-control comparison }\end{array}$ \\
\hline $\begin{array}{l}\text { Sanders et al } \\
1981\end{array}$ & $\begin{array}{l}\text { Fathers of all children dying } \\
\text { from neoplasms in England and } \\
\text { Wales } 1959-63(4395) \text { and } \\
1970-72(2525)\end{array}$ & $\begin{array}{l}\text { Fathers of all children dying } \\
\text { from all other causes in England } \\
\text { and Wales } 1959-63(112840) \\
\text { and } 1970-72(54806)\end{array}$ & Death certificates & $\begin{array}{l}\text { No overall association between } \\
\text { deaths from neoplasms and } \\
\text { hydrocarbon-related occupations but } \\
\text { possibly between kidney tumours and } \\
\text { hydrocarbon-related occupations } \\
\text { An increased risk for children of } \\
\text { parents in higher social classes }\end{array}$ \\
\hline $\begin{array}{l}\text { Gold et al } \\
1982\end{array}$ & $\begin{array}{l}\text { Parents of } 43 \text { children } \\
\text { developing leukaemia from } \\
1969-74 \text { and } 70 \text { children } \\
\text { diagnosed with brain tumours } \\
\text { from } 1965-74 \text { in the Baltimore } \\
\text { Standard Metropolitan } \\
\text { Statistical Area }\end{array}$ & $\begin{array}{l}\text { Two groups: } \\
\text { Parents of children with no } \\
\text { known malignant disease } \\
\text { selected from birth certificates at } \\
\text { the Maryland State Health } \\
\text { Department and matched for } \\
\text { date of birth, sex and race } \\
\text { Parents of children with } \\
\text { malignancies other than } \\
\text { leukaemia or brain tumours and } \\
\text { matched for sex, date of } \\
\text { diagnosis, age at diagnosis and } \\
\text { race }\end{array}$ & $\begin{array}{l}\text { Interviews with } \\
\text { mothers }\end{array}$ & $\begin{array}{l}\text { The results of this study do not } \\
\text { indicate a relationship between } \\
\text { parental occupation and cancer in the } \\
\text { offspring } \\
\text { The only significant association was } \\
\text { between paternal motor vehicle } \\
\text { related occupations, for both } \\
\text { leukaemia patients and brain tumour } \\
\text { patients, and their cancer controls }\end{array}$ \\
\hline $\begin{array}{l}\text { Shaw et al } \\
1984\end{array}$ & $\begin{array}{l}\text { Fathers of } 255 \text { childhood } \\
\text { leukaemia cases born after } 1964 \\
\text { that were reported to the } \\
\text { California Tumor Registry and } \\
\text { diagnosed between } 1975 \text { and } \\
1980\end{array}$ & $\begin{array}{l}\text { Fathers of } 510 \text { children of the } \\
\text { same sex as the index case whose } \\
\text { birth certificates immediately } \\
\text { preceded and followed the index } \\
\text { case }\end{array}$ & Birth certificates & $\begin{array}{l}\text { No relationship between paternal } \\
\text { occupation and childhood leukaemite }\end{array}$ \\
\hline $\begin{array}{l}\text { Wilkins and Sinks } \\
1984\end{array}$ & $\begin{array}{l}\text { Fathers of } 62 \text { patients with } \\
\text { Wilms' tumour identified } \\
\text { through the Columbus (Ohio) } \\
\text { Children's Hospital Tumor } \\
\text { Registry }\end{array}$ & $\begin{array}{l}\text { Two groups: } \\
\text { Fathers of children matched for } \\
\text { sex, race and year of birth } \\
\text { Fathers of children matched for } \\
\text { sex, race, year of birth and } \\
\text { mother's county of residence } \\
\text { when the child was born }\end{array}$ & Birth certificates & $\begin{array}{l}\text { No statistically significant association } \\
\text { was found between paternal } \\
\text { occupations defined as hydrocarbon } \\
\text { or lead related and Wilms' tumour in } \\
\text { offspring }\end{array}$ \\
\hline
\end{tabular}

